\title{
Antimalarial Activity of C-10 Substituted Triazolyl Artemisinin
}

\author{
Gab-Man Park', Hyun Park², Sangtae Oh³ Seokjoon Lee,** \\ ${ }^{1}$ Department of Medical Environmental Biology, Catholic Kwandong University College of Medicine, Gangneung 25601, Korea; ${ }^{2}$ Department of \\ Environmental Medical Biology, Wonkwang University College of Medicine, Iksan 54538, Korea; ${ }^{3}$ Department of Basic Science, Catholic Kwandong \\ University College of Medicine, Gangneung 25601, Korea; ${ }^{4}$ Department of Pharmacology, Catholic Kwandong University College of Medicine,
} Gangneung 25601, Korea

\begin{abstract}
We synthesized C-10 substituted triazolyl artemisinins by the Huisgen cycloaddition reaction between dihydroartemisinins (2) and variously substituted 1, 2, 3-triazoles (8a-8h). The antimalarial activities of 32 novel artemisinin derivatives were screened against a chloroquine-resistant parasite. Among them, triazolyl artemisinins with electron-withdrawing groups showed stronger antimalarial activities than those shown by the derivatives having electron-donating groups. In particularly, $m$-chlorotriazolyl artemisinin (9d-12d) showed antimalarial activity equivalent to that of artemisinin and could be a strong drug candidate.
\end{abstract}

Key words: Antimalarial activity, artemisinin, dihydroartemisinin, substituted triazolyl artemisinin, synthesis

The naturally occurring sesquiterpene endoperoxide artemisinin (1), which was isolated from Artemisia annua L., [1] serves as an interesting lead compound in the development of many drugs [2]. Artemisinin (1) is an important lead compound in the development of antimalarial drugs, especially against chloroquine-resistant strains of Plasmodium falciparum [3-6]. In addition, artemisinin (1) and its reductive product, dihydroartemisinin (2), have been used to develop novel anticancer agents [7-9]. To overcome the limitation of the poor water- and oil-soluble nature of 1 , many trials have been conducted to synthesize artemisinin derivatives such as acetal-type artemisinin derivatives (3) from dihydroartemisinin (2) [10$13]$ and nonacetal-type derivatives $(4)[14,15]$. We also synthesized thiophenyl- (5) and benzenesulfonyl-dihydroartemisinin (6) and evaluated their antimalarial activities [16]. By adding a sulfidyl or sulfonyl group on the C-10 anomeric center of 1 (Fig. 1), we observed an improvement in antimalarial activity [16]. We synthesized novel artemisinin derivatives as shown in Fig. 1 because the acetal group at the $\mathrm{C}-10$ position of artemisinin (1) confers chemical and biological instability

\footnotetext{
• Received 8 August 2017, revised 21 November 2017, accepted 5 December 2017.

*Corresponding author (sjlee@cku.ac.kr)

(C) 2017, Korean Society for Parasitology and Tropical Medicine

This is an Open Access article distributed under the terms of the Creative Commons Attribution Non-Commercial License (http://creativecommons.org/licenses/by-nc/4.0) which permits unrestricted non-commercial use, distribution, and reproduction in any medium, provided the original work is properly cited.
}

[17] and causes neuronal toxicity [18]. Previous reports on its structure-activity relationship (SAR), reveal an unmet need for structural derivatization of artemisinin to facilitate novel antimalarial drug discovery. In particularly, Haynes recently reported that artemisone (10-alkylaminoartemisinin), N-sulfonyl11-azaartemisinin, and N-carbonyl-11-azaartemisinin, having nitrogen groups at the $\mathrm{C}-10$ position, showed increment of antimalarial property $[19,20]$.

Consequently, we could safely assume that the introduction of additional nitrogen groups at the C-10 position of 1 will afford novel artemisinin derivatives with improved antimalarial activities. Therefore, we designed and synthesized various 10-substituted triazolylartemisinins (7) and tested their antimalarial activities against chloroquine-resistant $P$. falciparum (50005 = FCR-3/Gambia subline F-86).

Novel 10-substituted triazolyl artemisinin analogs (9a-9h, 10a-10h, 11a-11h, and 12a-12h) were obtained by the Huisgen cycloaddition reaction between dihydroartemisinins (2) and variously substituted 1, 2, 3-triazoles (8a-8h) in the presence of an acid catalyst, $\mathrm{BF}_{3} \mathrm{Et}_{2} \mathrm{O}$, at room temperature. By altering the reactant stoichiometric ratio, the various 10-substituted triazolyl artemisinin analogs were synthesized. A reactant stoichiometric ratio of 1:1 for dihydroartemisinin (2) and triazoles (8a$8 \mathrm{~h}$ ) yielded 3 kinds of diastereomers $(9,10$, and 11). However, when the ratio was changed to $1: 3$, compound 12 was obtained instead of 9. The stereochemistry of compounds (12a- 


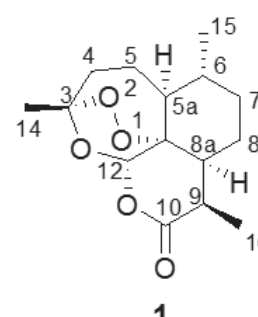

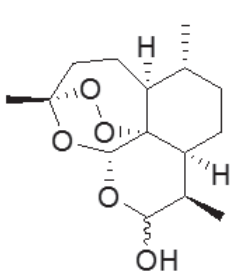

2

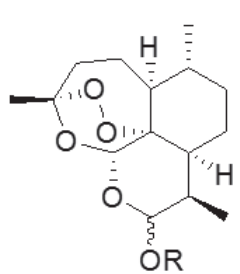

3

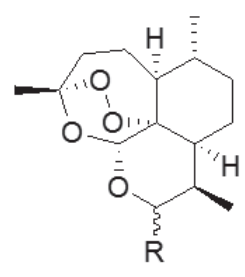

4

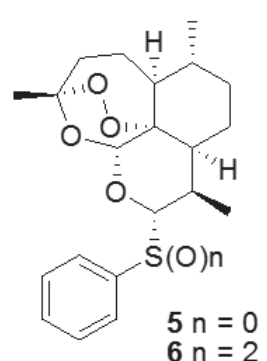

$6 n=2$

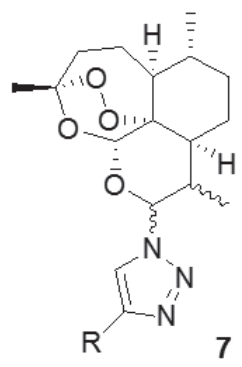

Fig. 1. Structure of artemisinin and artemisinin derivatives with diverse functional group.

$12 \mathrm{~h}$ ) were different from that of compounds with the C-9 methyl group (9a-9h) [21-23]. By using the above 2 different reaction conditions, 32 novel artemisinin derivatives having a substituted triazole group were obtained.

The culture-adapted chloroquine-resistant strain of $P$. falciparum, FCR-3/Gambia subline F-86, obtained from ATCC $[24,25]$. Further RPMI 1,640 medium containing hypoxanthine supplemented with HEPES buffer, sodium bicarbonate, human A serum, glutamine, gentamicin, and uninfected human oerythrocytes was used.

The in vitro antimalarial assays were conducted by modifying of the semi-automated microdilution technique described by Desjardins et al. [26] and the technique based on radiolabeled $\left[\mathrm{H}^{3}\right]$ hypoxanthine incorporation described by Delhaes et al. [27]. Antimalarial activity testing of the synthetic library was carried out in 96-well microtiter plates. Stock solutions of each of the test compounds were pre-diluted with complete culture medium (RPMI 1,640 supplemented with 10\% pooled human A serum), and were serially diluted 2fold in duplicate. The final concentrations ranged from 1.96 to $250 \mathrm{nmole} / \mathrm{L}$ for artemisinin and its derivatives from 11.2 to $1,435 \mathrm{nmole} / \mathrm{L}$ for chloroquine. After addition of a suspension of parasitized erythrocytes in complete culture medium (200 per well, 0.7\% initial parasitemia with a majority in ring stages, $1.8-2 \%$ hematocrit) and $\left[\mathrm{H}^{3}\right]$ hypoxanthine ( $1 \mu \mathrm{l}$ per well; TRK74, Amersham, UK), the test plates were incubated at $37^{\circ} \mathrm{C}$ for $24 \mathrm{hr}$ in an atmosphere of $5 \% \mathrm{O}_{2}, 5 \% \mathrm{CO}_{2}$, and $90 \% \mathrm{~N}_{2}$. Proliferation of the parasites was evaluated after the incorporation of radiolabeled $\left[\mathrm{H}^{3}\right]$ hypoxanthine into the nucleic acids of parasites and measurement in a liquid scintillation spectrometer (Packard Instrument Co., Downers Grove, Illinois, USA). Half maximal inhibitory concentration $\left(\mathrm{IC}_{50}\right)$ values refer to molar concentrations of a drug causing 50\% reduction in $\left[\mathrm{H}^{3}\right]$ hypoxanthine incorporation, compared to that in drug-free control wells. $\mathrm{IC}_{50}$ values were estimated by linear regression analysis of log-dose-response curves.

Initially, we tested the antimalarial activities of chloroquine and artemisinin, and considered them as positive controls against the chloroquine-resistant parasite ( $50005=$ FCR-3). We then compared the potencies our synthetic artemisinin derivatives having a substituted triazole group, with those of the positive controls. Due to the chloroquine-resistant nature of the parasite, we observed a low potency for chloroquine $\left(\mathrm{IC}_{50}\right.$ $=101.2 \pm 25.2 \mathrm{nM}$ ) compared to that observed for artemisinin $\left(\mathrm{IC}_{50}=1.4 \pm 0.52 \mathrm{nM}\right)$. The potencies of antimalarial activities varied greatly depending on the structure of the triazole groups and the stereochemistry of the compounds as shown in Table 1. In relation to the variation in potency due to the structural change of the triazole groups, the most potent compounds were the artemisinin derivatives having the m-chlorophenyl tertrazole group. The $\mathrm{IC}_{50}$ values for compounds $9 \mathrm{~d}, 10 \mathrm{~d}, 11 \mathrm{~d}$, and $12 \mathrm{~d}$ were $2.5,4.2,1.3$, and $3.7 \mathrm{nM}$, respectively. Due to the electron-withdrawing nature of the chloride group in compounds 9d-12d, we expected compounds 9c-12c, 9e-12e, and of $9 \mathrm{~h}-12 \mathrm{~h}$, having similar electron-withdrawing fluoride group to also show potent antimalarial activities. However, among 9c-12c, only 2 diastereomers (10c and 11c) showed antimalarial activities with similar potencies to those of the most potent antimalarial candidates (9d-12d) among the synthetic substituted triazolyl artemisinin derivatives and artemisinin. Compounds of 9e-12e, having an electron-withdrawing trifluoromethyl group $\left(-\mathrm{CF}_{3}\right)$, exhibited moderately potent antimalarial activities that were nevertheless not as potent as those of compounds $9 \mathrm{~d}-12 \mathrm{~d}$ and artemisinin. However, compounds $9 \mathrm{~h}-$ $12 \mathrm{~h}$, having the strongest electron-withdrawing group (-F), exhibited a weak antimalarial activity. When considering the effect of a functional group attached on triazole ring, its electron (electron-donating or -withdrawing character) plays an important role in enhancing antimalarial activity. Substituted triazolyl artemisinin compounds with electron-withdrawing groups 
Table 1. Antimalarial activity of C-10 substituted triazolyl artemisinin against chloroquine-resistant parasite

\begin{tabular}{|c|c|c|c|}
\hline Compounds & $\begin{array}{l}\text { Inhibitory activity of chloroquine-resistant } \\
\text { parasite }^{2}(50005=\text { FCR-3), nM }\end{array}$ & Compounds & $\begin{array}{l}\text { Inhibitory activity of chloroquine-resistant } \\
\text { parasite }^{\text {( }}(50005=\text { FCR-3), nM }\end{array}$ \\
\hline $9 a$ & $51.7 \pm 5.20^{b}$ & $9 e$ & $13.9 \pm 1.89$ \\
\hline $10 \mathrm{a}$ & $51.9 \pm 9.23$ & $10 e$ & $4.7 \pm 1.20$ \\
\hline $11 a$ & $46.4 \pm 3.52$ & $11 e$ & $4.6 \pm 0.56$ \\
\hline $12 a$ & $34.7 \pm 2.54$ & $12 \mathrm{e}$ & $9.2 \pm 2.36$ \\
\hline $9 b$ & $136.6 \pm 15.3$ & $9 f$ & $338.3 \pm 24.3$ \\
\hline $10 \mathrm{~b}$ & $48.5 \pm 5.23$ & $10 f$ & $99.0 \pm 15.2$ \\
\hline $11 b$ & $38.5 \pm 4.63$ & $11 f$ & $59.8 \pm 8.9$ \\
\hline $12 b$ & $160.0 \pm 25.3$ & $12 f$ & $199.2 \pm 14.3$ \\
\hline $9 c$ & $363.2 \pm 36.3$ & $9 g$ & $263.3 \pm 35.2$ \\
\hline $10 \mathrm{c}$ & $2.5 \pm 0.35$ & $10 \mathrm{~g}$ & $373.2 \pm 33.1$ \\
\hline $11 \mathrm{c}$ & $1.4 \pm 0.13$ & $11 \mathrm{~g}$ & $108.5 \pm 12.1$ \\
\hline $12 \mathrm{c}$ & $194.9 \pm 14.7$ & $12 \mathrm{~g}$ & $539.1 \pm 24.5$ \\
\hline $9 d$ & $2.5 \pm 0.24$ & $9 \mathrm{~h}$ & $193.2 \pm 12.4$ \\
\hline $10 d$ & $4.2 \pm 1.2$ & $10 \mathrm{~h}$ & $96.6 \pm 6.89$ \\
\hline $11 d$ & $1.3 \pm 0.12$ & $11 \mathrm{~h}$ & $198.3 \pm 19.5$ \\
\hline $12 d$ & $3.7 \pm 0.35$ & $12 \mathrm{~h}$ & $49.2 \pm 2.35$ \\
\hline Chloroquine & $101.2 \pm 25.2$ & Artemisinin (1) & $1.4 \pm 0.52$ \\
\hline
\end{tabular}

aThe inhibitory concentration was plotted as a function of the log scale concentration for compounds, and the curves were fitted using the Hill equation, $I \mathrm{C}_{50}=\left(1+\mid \mathrm{C}_{50} /[\text { compound }]^{n}\right)^{-1}$.

${ }^{b}$ Data of $I_{50}$ are presented as the mean $\pm S D(n=3)$.

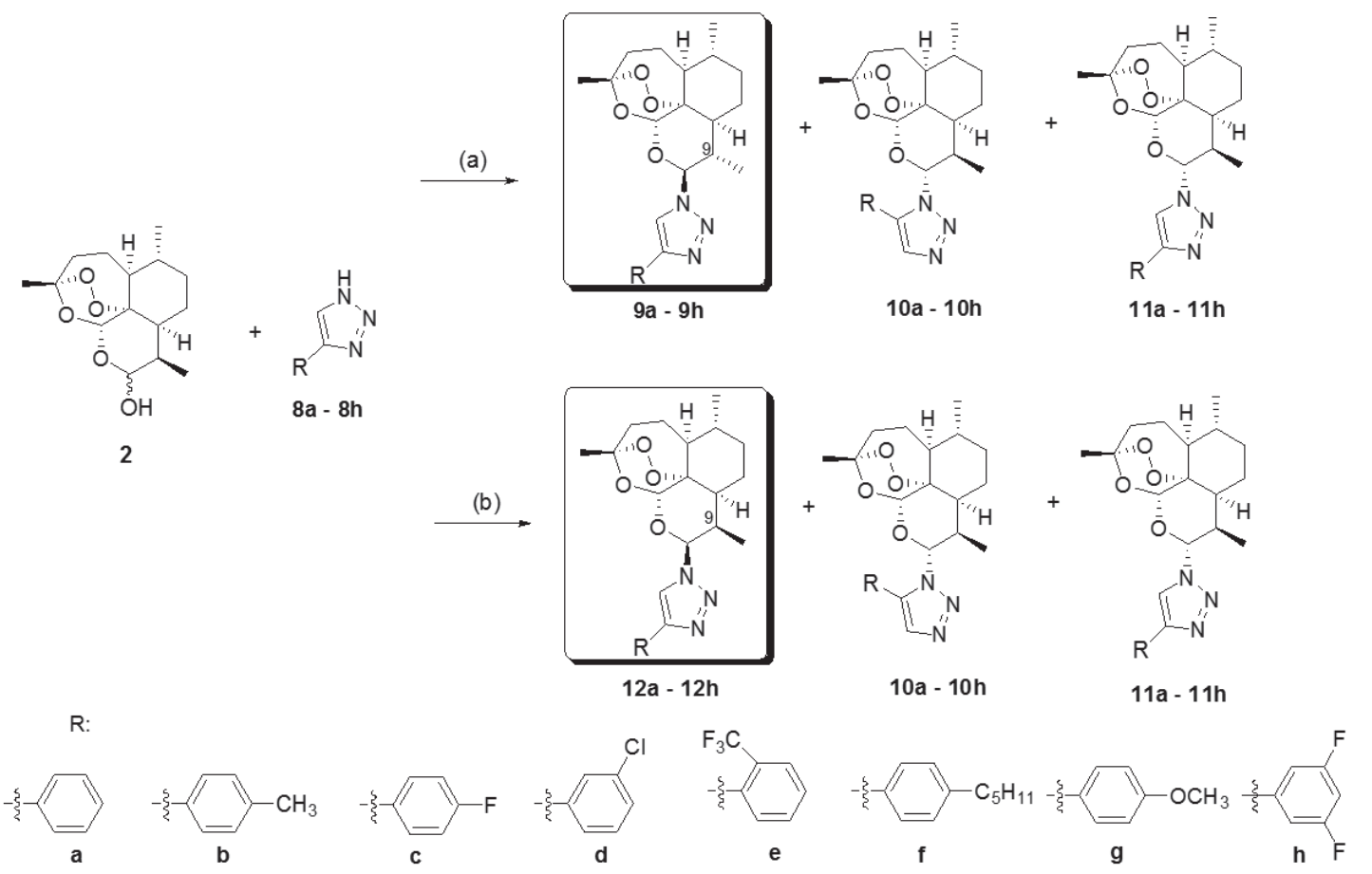

Fig. 2. Reagents and conditions. (a) Triazole (8a-8h, 1 eq), BF3Et2O (0.8 eq) methylene chloride, rt, 24h. (b) Triazole (8a-8h, 3 eq), BF3Et2O (0.8 eq) methylene chloride, it, 24h.

(-F, $-\mathrm{Cl}$, and $\left.-\mathrm{CF}_{3}\right)$ showed stronger antimalarial activities than those of artemisinin derivatives with electron-donating groups $\left(-\mathrm{H},-\mathrm{CH}_{3},-\mathrm{C}_{5} \mathrm{H}_{11}\right.$, and $\left.-\mathrm{OCH}_{3}\right)$. To improve the antimalarial activities of compounds with substituted triazolyl group in our synthesis library, we suggest synthesis of substituted triazolyl artemisinins that have $\mathrm{o}-\mathrm{Cl}$ and/or $\mathrm{p}-\mathrm{Cl}$, and other electron- 
withdrawing groups such as nitro, carbonyl, and nitrile groups. Further, while considering stereochemistry including regiochemistry, stereochemistry is not an important contributor to the functional group effects. As shown in Fig. 2, we synthesized four kinds of substituted triazolyl artemisinins by varying the stereochemistry at the C-9 and C-10 positions of artemisinin and by varying the regiochemistry of the triazole group under the 2 reaction conditions. Among the 4 kinds of stereoisomers and regioisomers synthesized, the most potent isomer was $9 \beta, 10 \alpha$ compound (11). Fortunately, the yield of the reaction is high, and it is easy to obtain the amount of substance necessary for carrying out in vivo experiments.

In conclusion, by the Huisgen cycloaddition reaction between dihydroartemisinins (2) and variously substituted 1, 2, 3-triazoles (8a-8h), we synthesized 4 kinds of stereoisomers and regioisomers of C-10 substituted triazolyl artemisinins under 2 reaction conditions. Among all the library compounds that we tested, $m$-chlorotriazolyl artemisinin $(9 \mathrm{~d}-12 \mathrm{~d})$ and $o$ trifluoromethyltriazolyl artemisinin (9e-12e) showed potent antimalarial activities against chloroquine-resistant parasite strain $(50005=$ FCR-3). When considering the preliminary structure-activity relationship (SAR), electron-withdrawing property of the phenyl group attached to the triazole group plays a more important role in increasing the antimalarial activity than that played by stereochemistry. In particulary, the $m$-chlorotriazolyl derivatives of artemisinin (9d-12d) promises to be a strong drug candidate for novel antimalarial drug discovery.

\section{ACKNOWLEDGMENT}

This work was supported by National Research Foundation of Korea (NRF no. 2015M1A5A1037230) and by the research fund of Catholic Kwandong University.

\section{CONFLICT OF INTEREST}

We have no conflict of interest related to this work.

\section{REFERENCES}

1. Klayman DL. Qinghaosu (artemisinin): an antimalarial drug from China. Science 1985; 228: 1049-1055.

2. Lee $S$. Artemisinin, promising lead natural product for various drug developments. Mini Rev Med Chem 2007; 7: 411-422.

3. Luo XD, Shen CC. The chemistry, pharmacology, and clinical applications of qinghaosu (artemisinin) and its derivatives. Med Res Rev 1987; 7: 29-52.

4. Jung M. Current developments in the chemistry of artemisinin and related compounds. Curr Med Chem 1994; 1: 35-49.

5. Haynes RK, Vonwiller SC. From Qinghao, marvelous herb of antiquity, to the antimalarial trioxane qinghaosu-and some remarkable new chemistry. Acc Chem Res 1997; 30: 73-79.

6. Vroman JA, Alvim-Gaston M, Avery MA. Current progress in the chemistry, medicinal chemistry and drug design of artemisinin based antimalarials. Curr Pharm Design 1999; 5: 101-138.

7. Beekman AC, Barentsen ARW, Woerdenbag HJ, Van Uden W, Pras N, Konings AW, el-Feraly FS, Galal AM. Stereochemistry-dependent cytotoxicity of some artemisinin derivatives. J Nat Prod 1997; 60: 325-330.

8. Jung M, Lee S, Ham J, Lee K, Kim H, Kim SK. Antitumor activity of novel deoxoartemisinin monomers, dimers, and trimer. J Med Chem 2003; 46: 987-994.

9. Posner GH, Paik IH, Sur S, McRiner AJ, Borstnik K, Xie S, Shapiro TA. Orally active, antimalarial, anticancer, artemisinin-derived trioxane dimers with high stability and efficacy. J Med Chem 2003; 46: 1060-1065.

10. Brewer TG, Peggins JO, Grate SJ, Petras JM, Levine BS, Weina PJ, Swearengen J, Heiffer MH, Schuster BG. Neurotoxicity in animals due to arteether and artemether. Trans R Soc Trop Med Hyg 1994; 88: 33-36.

11. Lin AJ, Lee M, Klayman DL. Antimalarial activity of new watersoluble dihydroartemisinin derivatives. 2 . Stereospecificity of the ether side chain. J Med Chem 1989; 32: 1249-1252.

12. Lin AJ, Klayman DL, Milhous WK. Antimalarial activity of new water-soluble dihydroartemisinin derivatives. J Med Chem 1987; 30: 2147-2150.

13. Lin AJ, Miller RE. Antimalarial activity of new dihydroartemisinin derivatives. 6. alpha-Alkylbenzylic ethers. J Med Chem 1995; 38: 764-770.

14. Jung M, Li X, Bustos DA, ElSohly HN, McChesney JD. A short and stereospecific synthesis of (+)-deoxoartemisinin and (-)-deoxodesoxyartemisinin. Tetrahedron Lett. 1989; 44: 5973-5976.

15. Jung M, Li X, Bustos DA, elSohly HN, McChesney JD, Milhous WK. Synthesis and antimalarial activity of (+)-deoxoartemisinin. J Med Chem 1990; 33: 1516-1518.

16. Lee S, Oh S, Park GM, Kim TS, Ryu JS, Choi HK. Antimalarial activity of thiophenyl- and benzenesulfonyl-dihydroartemisinin. Korean J Parasitol 2005; 43: 123-126.

17. Jung M, Lee S. Stability of acetal and non acetal-type analogs of artemisinin in simulated stomach acid. Bioorg Med Chem Lett 1998; 8: 1003-1006.

18. Gordi T, Lepist EI. Artemisinin derivatives: toxic for laboratory animals, safe for humans? Toxicol Lett 2004; 147: 99-107.

19. Haynes RK, Wong HN, Lee KW, Lung CM, Shek LY, Williams ID, Croft SL, Vivas L, Rattray L, Stewart L, Wong VK, Ko BC. Preparation of N-sulfonyl- and N-carbonyl-11-azaartemisinins with greatly enhanced thermal stabilities: in vitro antimalarial activities. Chem Med Chem 2007; 2: 1464-1479. 
20. Haynes RK, Fugmann B, Stetter J, Rieckmann K, Heilmann HD, Chan HW, Cheung MK, Lam WL, Wong HN, Croft SL, Vivas L, Rattray L, Stewart L, Peters W, Robinson BL, Edstein MD, Kotecka B, Kyle DE, Beckermann B, Gerisch M, Radtke M, Schmuck G, Steinke W, Wollborn U, Schmeer K, Römer A. Artemisone--a highly active antimalarial drug of the artemisinin class. Angew Chem Int Ed Engl 2006; 45: 2082-2088.

21. Cho S, Oh S, Um Y, Jung JH, Ham J, Shin WS, Lee S. Synthesis of 10-substituted triazolyl artemisinins possessing anticancer activity via Huisgen 1,3-dipolar cycloaddition. Bioorg Med Chem Lett 2009; 19: 382-385.

22. Oh S, Shin WS, Ham J, Lee S. Acid-catalyzed synthesis of 10-substituted triazolyl artemisinins and their growth inhibitory activity against various cancer cells. Bioorg Med Chem Lett 2010; 20: 4112-4115.

23. Lee S. Synthesis of $10 \beta$-substituted triazolyl artemisinins and their growth inhibitory activity against various cancer cells. Bull Korean Chem Soc 2011; 32: 737-740.

24. Nguyen-Dinh P, Trager W. Plasmodium falciparum in vitro: determination of chloroquine sensitivity of three new strains by a modified 48-hour test. Am J Trop Med Hyg 1980; 29: 339-342.

25. Jensen JB, Trager W. Plasmodium falciparum in culture: establishment of additional strains. Am J Trop Med Hyg 1978; 27: 743746.

26. Desjardins RE, Canfield CJ, Haynes JD, Chulay JD. Quantitative assessment of antimalarial activity in vitro by a semiautomated microdilution technique. Antimicrob Agents Chemother 1979; 16: 710-718.

27. Delhaes L, Biot C, Berry L, Delcourt P, Maciejewski LA, Camus D, Brocard JS, Dive D. Synthesis of ferroquine enantiomers: first investigation of effects of metallocenic chirality upon antimalarial activity and cytotoxicity. Chembiochem 2002; 3: 418-423. 
